Research Article

\title{
Bibliometric Analysis on Geriatric Nursing Research in Web of Science (1900-2020)
}

\author{
Arezoo Ghamgosar $\mathbb{D}^{1,2}$ Maryam Zarghani $\mathbb{D}^{1},{ }^{1}$ and Leila Nemati-Anaraki $\mathbb{D}^{3}$ \\ ${ }^{1}$ Department of Medical Library and Information Sciences, School of Health Management and Information Sciences, Iran University \\ of Medical Sciences, Tehran 1996713883, Iran \\ ${ }^{2}$ Medical Biotechnology Research Center, School of Paramedicine, Guilan University of Medical Sciences, Rasht 44817, Iran \\ ${ }^{3}$ Department of Medical Library and Information Sciences, School of Health Management and Information Sciences, Iran University \\ of Medical Sciences, Tehran, Iran
}

Correspondence should be addressed to Arezoo Ghamgosar; ghamgosar.a@iums.ac.ir and Leila Nemati-Anaraki; nematianaraki.l@iums.ac.ir

Received 16 May 2021; Accepted 12 September 2021; Published 28 September 2021

Academic Editor: Cristiano Capurso

Copyright (c) 2021 Arezoo Ghamgosar et al. This is an open access article distributed under the Creative Commons Attribution License, which permits unrestricted use, distribution, and reproduction in any medium, provided the original work is properly cited.

\begin{abstract}
Objective. Aging is a growing public health concern for people, organizations, and governments. The current study was undertaken to provide insights into the global research output on geriatric nursing. Methods. A bibliometric study was implemented using the WoS database for the period from 1900 to 2020. Various tools and measures were used to analyze and visualized. Results. The search strategy found 4923 papers. The oldest paper was written by Beverly C. Andre in 1953. As team size increases, so does the number of citations. The USA was the active country and the highest number of coauthors. New York University was an active institution. Stig Karlsson was the most active author in Geriatric Nursing with 28 articles from Sweden, followed by Koen Milisen and Sandman, with 26 articles each from Sweden and Belgium. The most frequent words in this field were depression, malnutrition, education, Alzheimer's disease, and dementia. The latest research themes in this field were COVID-19, interprofessional locomotive syndrome, emergency nursing, and public health. The most influential papers were specified. Journal of the American Geriatrics Society was the most active journal. Conclusions. Geriatric nursing is a rooted field and has received special attention in the last decade. Policymakers, especially in developing countries, should pay attention to geriatric nursing as a specialty of nursing to solve aging issues they would face considering the increasing elderly population.
\end{abstract}

\section{Introduction}

Aging is the most complex human phenotype and a healthrelated concern for individuals, organizations, and governments [1]. It is essentially a biological phenomenon and is now a global issue $[2,3]$. Aging, which is widely defined as a reduction in the time-dependent function of organs, has affected most living things and has created curiosity and excitement throughout human history [4]. The United Nation has a global estimate of 703 million individuals aged $>65$ years based on statistics provided by the World Population Prospects 2019 (United Nations, 2019), indicating an increase from $6 \%$ in 1990 to $9 \%$ in 2019 . The population of the elderly is estimated to reach 1.5 billion in 2050 (16\%, one in six people) [5]. Therefore, governments are rapidly implementing policies that suit the phenomenon of aging in the population [6].

In response to these facts as a strategy, the health systems of different countries have paid special attention to the role of geriatric nursing [7]. Geriatric nursing emerged as a specialty after the 1950s. In meeting the needs of the elderly, the need for trained nurses with specialized scientific training to meet the care needs of the elderly was essential $[8,9]$. This interest was followed by a great desire to conduct scientific 
research in this field [10]. Therefore, during the past years, scientific production in the field of geriatric nursing has increased $[4,11]$ and has now flourished [12].

Bibliometrics has become a central component of research evaluation [13]. Bibliometric analysis can offer a general, quantitative, and qualitative overview of a specific topic with a vast background. In particular, it can express the evolution and trend of scientific development in a field, identify the advantages and newly emerging ideas, and evaluate the achievements and influence of countries, institutions, journals, papers, and individuals [14]. Bibliometrics as a global standard is the crossdisciplinary science of quantitative analysis of all knowledge carriers by mathematical, bibliographical, and statistical methods $[15,16]$. It plays a significant role, as a valuable research method, for quantifying scientific works, discovering interactions among scientists, and understanding recent advances in research [17]. Its methodologies generally use information technology to process and analyze quantitative and qualitative data from bibliographic information and provide meaningful implications [18]. The number of citations is the most frequently used indicator in evaluating the quality of papers, researchers, research centers, and universities [19] and evaluating the impact of an article on the existing literature [20].

Accordingly, the Web of Science (WoS) is often used for performing bibliometric analyses. The present study is the first comprehensive scientometric study of geriatric nursing. Evaluation of texts and presenting a comprehensive image of texts with respect to issues such as description, trend, and citation analysis of results, the value of team size, active countries, active institutions, international research collaboration, prolific authors, research networks of authors, research themes, most cited papers, and active journals can expand and produce new knowledge.

The findings are valuable for geriatric nursing researchers also for policy decision makers, top-level managers, politicians, and academic librarians. To the best of our knowledge, there is no bibliometric study and visualization map on geriatric nursing literature. Herein, this study fills this gap in the literature by conducting a bibliometric study of the geriatric nursing analysis.

\section{Materials and Methodology}

2.1. Data Source. A bibliometric study was implemented using the Web of Science (WoS) Core Collection for the period from 1900 to 2020 . The WoS core collection database is a selective citation index of scientific and scholarly publishing consisting of journals, proceedings, books, and data compilations. The WoS is a selective, structured, and balanced database, not merely a catalog of publications. It has complete citation linkages and enhanced metadata supporting various information needs. Data are used by the WoS for mainly research performance evaluation, including rankings, mapping topics and monitoring trends, and investigating aspects of the history and sociology of science and scholarly activity [21].
2.2. Search Strategy. The WoS database was searched in 7 November 2020. Medical subject headings were used and followed recommendations of terms for search. In order to cover all the appropriate search terms, systematic review studies of previous geriatric nursing were used, and geriatric nurses were consulted to obtain additional terms used in practice $[2,10]$. The search terms that would be used to create a search query were then finalized. The search strategy was designed with search terms including (senior* OR aged* OR Elder* OR Geri*OR age* OR "OlderAdult*" OR geriatric* OR aging OR "very elderly" OR "frail elderly" OR “aged 80 and over”) AND (geriatric nurs* OR gerontological nurs $*$ OR gerontologic nurs $*$ ), while being limited to the field of "Topic." The field of "language" was limited to "English," and the field of "document types" was limited to "article." Only original research articles were included, and other types of articles such as letters to editors, reports, notes, short communications, short surveys, patents, and undefined were excluded.

2.3. Data Collection. The authors used the following indicators: description, trend, and citation analysis of results, the value of team size, active countries, active institutions, international research collaboration, prolific authors, research networks of authors, research themes, most cited papers, and active journals. After data collection, all data were exported in plain text and Excel format. The record content was limited to the full record and cited references. After this stage, WoS options, Microsoft Excel, version 2013, and some bibliometrics software, including Bibexcel, VOSviewer program (version 1.6.7) (Leiden University, Leiden, The Netherlands), were used.

2.4. Bibliometric and Visualized Analysis. To determine description, trend, and citation analysis of results, the online option of the WoS and Bibexcel, version 2008-08 was used. Using Bibexcel and by calculating the correlation between the number of authors and median citation to each article, the team size value was extracted. In order to receive active countries, active institutions, and prolific authors, we used bibliographic coupling analysis. A python script was written to unify author names with different spellings. The authors applied the VOSViewer software program (version 1.6.7). This software displays the area of international research collaboration, research networks of authors, and author keyword visualization of literature on research themes [22]. To obtain the most cited papers, after performing the search strategy, the retrieved results were limited to the field of "time cited-highest to lowest" and sorted accordingly. The authors applied the Bradford Law to obtain active journals in the field of geriatric nursing [23]. According to this bibliometric law, a small number of scientific journals is responsible for the great majority of publications on specific different themes and thus correspond to the core of scientific production [24]. Initially, 990 journals covering 4923 articles were divided into three categories so that the number of articles in all categories will be approximately equal. The first core was then introduced as the Bradford core. 


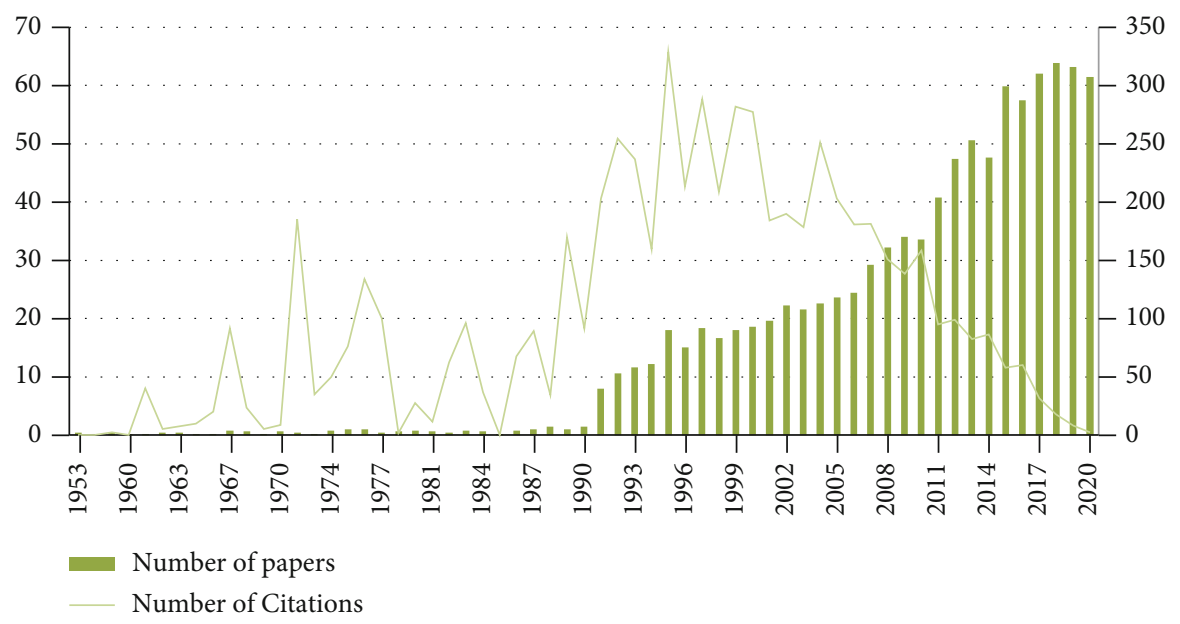

Figure 1: Number of papers and number of citations of Geriatric Nursing (1990-2020).

\section{Results}

3.1. Description, Trend, and Citation Analysis of Results. The search strategy found 4923 total papers and an average of 158 papers per year. The retrieved papers received 112,461 citations, an average of 22.91 citations per paper. The total citing papers were 77,196 . The $h$-index of the retrieved papers was 125 (Figure 1). The oldest paper was written by Beverly C. Andre in 1953 entitled "Nursing Programs in Schools of Nursing" in the Journal of Gerontology [25]. His affiliation is Department of Nursing, Northwestern State College Natchitoches, Louisiana.

3.2. Value of Team Size. Figure 2 shows the team size distribution and the average citation of each document in geriatric nursing. 18215 authors have contributed to 4923 scientific papers in the field of geriatric nursing. Accordingly, the pattern of coauthorship in this field was four, which means that $15 \%$ of scientific articles in this field have been written in collaboration with a team of four people. By removing outdated data in this subject area, there was a correlation between team size and average citations of 0.29 , which means that as team size increases, so does the number of citations. The highest average number of citations was related to an article by 34 authors of international cooperation, and 601 received citations. The title of this article is "Defeating Alzheimer's disease and other dementias: a priority for European science and society", published in The Lancet Neurology in 2016. Studies on patient care and related research, from basic to clinical, in Alzheimer's disease and other dementias should be organized in the future [26].

3.3. Active Countries. Ninety-three countries contributed to geriatric nursing papers, with $1862(37.822 \%)$ papers published in the USA, followed by Canada with 307 (6.236\%) and Australia with 292 (5.931\%). In terms of geographical distribution, three countries from the Americas, the countries that comprise the regions of North, Central, and South America, six countries from Europe, and one country from
Oceania were the most active. These countries account for almost $81 \%$ of all articles (Table 1 ).

3.4. Active Institutions. Institutions affiliated with American universities were the most active in this field. The next rankings were held by Canadian and Swedish universities. The top ten active institutions contributed to 693 papers $(12.755 \%)$. The top active institutions included eight in North America and two in Europe. New York University came in first with 97 articles, followed by the University of California Los Angeles with 93, the University of Toronto with 76, and the Karolinska Institutet with 65 (Table 2).

3.5. International Research Collaboration. Figure 3 shows a visualization map of international research collaboration among countries. The USA, Canada, and Australia are the countries that have published the largest number of scientific articles with 1786, 295, and 278 articles, respectively. Scientific papers from Northern Ireland, Scotland, Wales, the United Kingdom, and the USA have a higher average age and the countries with a background in this field. Indonesia, Mexico, Iran, Jordan, and Malaysia are also among the countries that have recently started publishing research articles in the field of geriatric nursing.

Figure 3 also reveals the coauthorship clustering of countries that have published more than five scientific articles in the field of geriatric nursing. Accordingly, forty-nine countries are located in nine clusters. Countries that have the same color are in the same cluster and have more allies. The USA is in purple with Japan, South Korea, and Taiwan, with the highest number of coauthors. Also, Canada is in another brown cluster with the highest number of coauthors with Israel and New Zealand. Most of Australia's counterparts are also dark blue, with Indonesia, Iran, Malaysia, China, Singapore, and Thailand, all of which are from Asia, especially Southeast Asia.

3.6. Prolific Authors. Stig Karlsson was the most active author in geriatric nursing with twenty-eight articles from Sweden, affiliated as professor at the department of nursing, followed by Koen Milisen and Per-Olof Sandman, with 


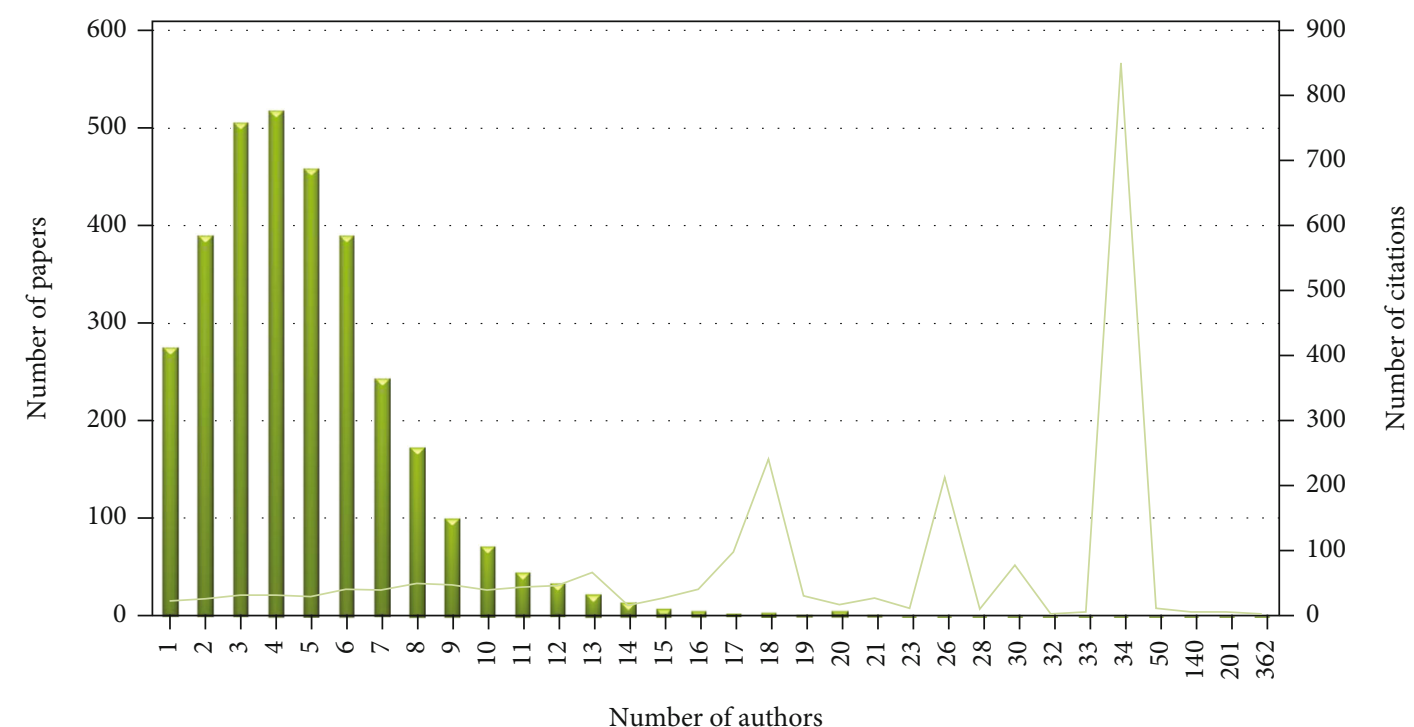

Number of author
Citations per paper

FIgURE 2: Team size and number of citations of Geriatric Nursing (1990-2020).

TABle 1: Top ten active countries in papers on Geriatric Nursing (1990-2020).

\begin{tabular}{lcc}
\hline Country & Frequency & $\%$ \\
& & $N=4923$ \\
\hline USA & 1862 & $37.822 \%$ \\
Canada & 307 & $6.236 \%$ \\
Australia & 292 & $5.931 \%$ \\
Germany & 253 & $5.139 \%$ \\
Netherlands & 251 & $5.099 \%$ \\
Sweden & 245 & $4.977 \%$ \\
France & 228 & $4.631 \%$ \\
England & 202 & $4.103 \%$ \\
Italy & 185 & $3.758 \%$ \\
Brazil & 160 & $3.250 \%$ \\
\hline
\end{tabular}

twenty-six articles each from Sweden, affiliated as professor at the department of nursing and Belgium, affiliated as professor at department of geriatric medicine (Table 3).

3.7. Research Networks of Authors. Figure 4 shows the clustering of authors who have published more than five scientific articles. In this figure, the size of each circle indicates the number of scientific articles by the author. This network is composed of 1268 authors. The closer the items are, the more relevant they are. Accordingly, as shown, 173 authors are in sixteen clusters.

3.8. Research Themes. The content of the articles was analyzed by analyzing authors' keywords in order to extract the general themes of the studies. Figure 5 shows the keywords of the authors in the field of geriatric nursing. Accordingly, by deleting the words "elderly" and "aged," the most frequent words in this field were depression, malnutrition, education, Alzheimer's disease, and dementia, respectively. The closer the keywords get from dark blue to yellow, the newer the words are to each other. Therefore, the latest research themes in this field were COVID-19, interprofessional locomotive syndrome, emergency nursing, and public health.

3.9. Most Cited Papers. Table 4 shows the eight most cited papers were published in the 1990s, and only two articles in 2004 and 2009 were among the most cited papers.

3.10. Active Journals. Table 5 introduces the twenty journals with the highest frequency in the publication of Geriatric Nursing in the WoS database. The Journal of the American Geriatrics Society was most active, followed by the Journal of American Medical Directors Association and Geriatric Nursing with a significant difference. The share of twenty active journals was 1763 articles in total. Among these journals, fifteen were related to geriatrics, three to nursing, one to psychogeriatrics, and one to medical sciences.

\section{Discussion}

This paper presents the first bibliometric analysis study of trends in geriatric nursing scholarship. Over the period of sixty-seven years, 4,923 articles in the field of geriatric nursing were described and cited, and some concepts were visualized for better understanding. The chart of publication of articles (Figure 1) showed that nursing is a discipline with a long history. According to the WoS database, the term geriatric nursing was first used in 1953 in an article entitled "Geriatric Nursing Programs in Schools of Nursing" [25]. The $h$-index of the retrieved papers on geriatric nursing was 125, which is higher than MERS-CoV [27] and Elder 
TABLE 2: Top ten active institutions in publishing papers on Geriatric Nursing (1990-2020).

\begin{tabular}{lccc}
\hline Institution & Country affiliation & Frequency & N $=4923$ \\
\hline New York University & USA & 97 & $1.970 \%$ \\
University California Los Angeles & USA & 93 & $1.889 \%$ \\
University Toronto & Canada & 76 & $1.544 \%$ \\
Karolinska Institutet & Sweden & 65 & 65 \\
The University of California, San Francisco & USA & 62 & $1.320 \%$ \\
University Minnesota & USA & 61 & $1.320 \%$ \\
University of Pennsylvania & USA & 61 & $1.259 \%$ \\
University of Pittsburgh & USA & 58 & $1.239 \%$ \\
Umeå University & Sweden & 55 \\
The University of North Carolina & USA & & $1.178 \%$ \\
\hline
\end{tabular}

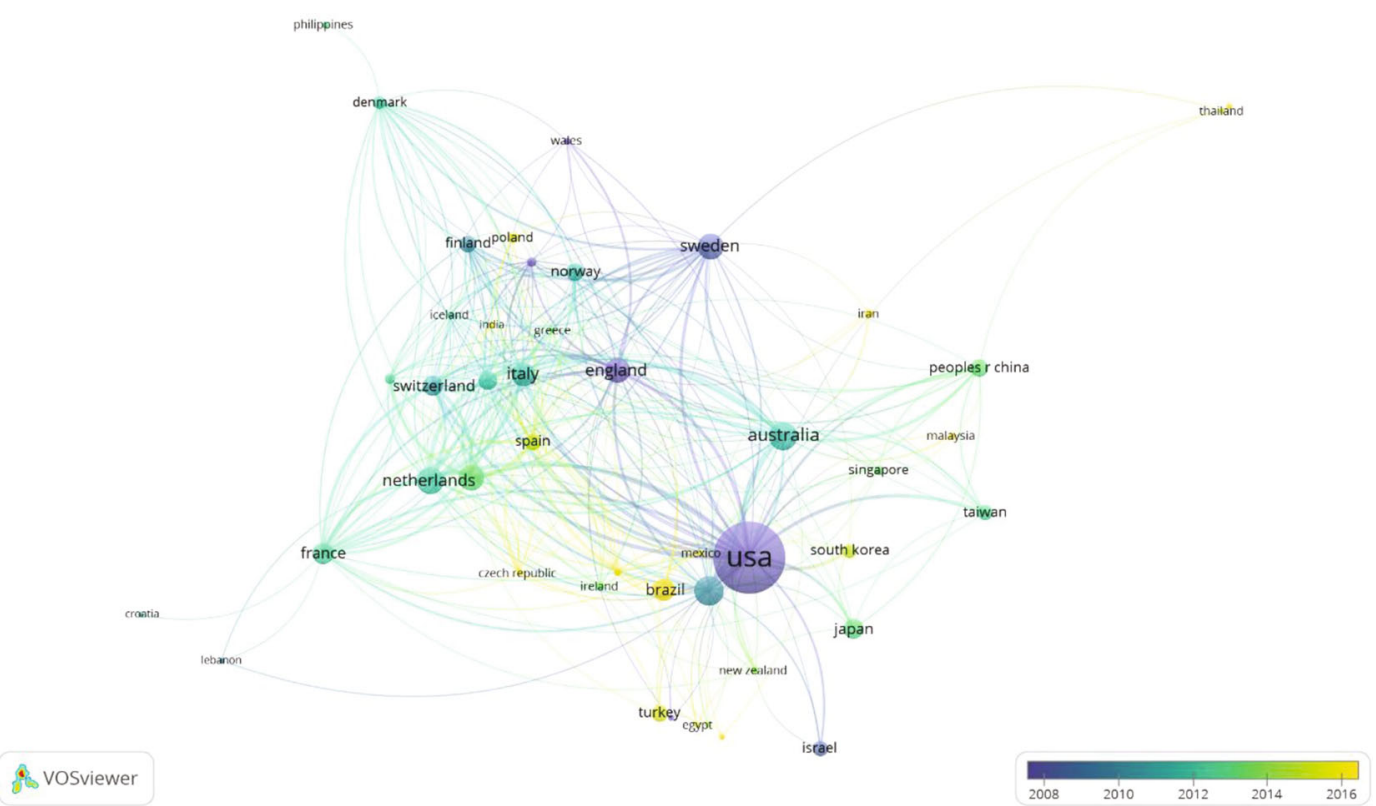

Figure 3: Visualization of international research collaboration with a minimum of 5 papers on Geriatric Nursing (1990-2020). For each of the 49 countries, the total strength of the coauthorship links with other countries will be calculated. The countries with the greatest total link strength will be selected.

TABLE 3: Top ten active authors in papers on Geriatric Nursing (1990-2020).

\begin{tabular}{lccc}
\hline Authors & Country affiliation & Frequency & $\begin{array}{c}\% \\
N=4923\end{array}$ \\
\hline Karlsson S & Sweden & 28 & $0.569 \%$ \\
Milisen K & Belgium & 26 & $0.528 \%$ \\
Sandman PO & Sweden & 26 & $0.528 \%$ \\
Bernabei R & USA & 25 & $0.508 \%$ \\
Gustafson Y & Sweden & 25 & $0.508 \%$ \\
Rubenstein LZ & France & 25 & $0.508 \%$ \\
Mezey M & USA & 24 & $0.488 \%$ \\
Vellas B & France & 23 & $0.467 \%$ \\
Capezuti E & USA & 22 & $0.447 \%$ \\
Pitkala KH & Finland & 21 & $0.427 \%$ \\
\hline
\end{tabular}

Abuse [28]. This indicates that the articles published over a period of time have been of considerable interest to readers and have had a significant impact on scientific texts. Published articles were divided into three time periods based on the publication pattern and citations received: the first period (1953-1990), the second period (1991-2010), and the third period (2011-2020). There were few articles in the first period. Despite the small number of articles, the number of citations to them was significant. Another point in the review of citations during this period was the article published in 1971, which was well-cited by readers, which was about nurses' attitudes concerning elderly patients [29]. Data analysis over the last seven decades has shown that since the second period, the growth of articles has accelerated slightly and has grown significantly compared to previous years, perhaps because of the introduction of the Internet and online 


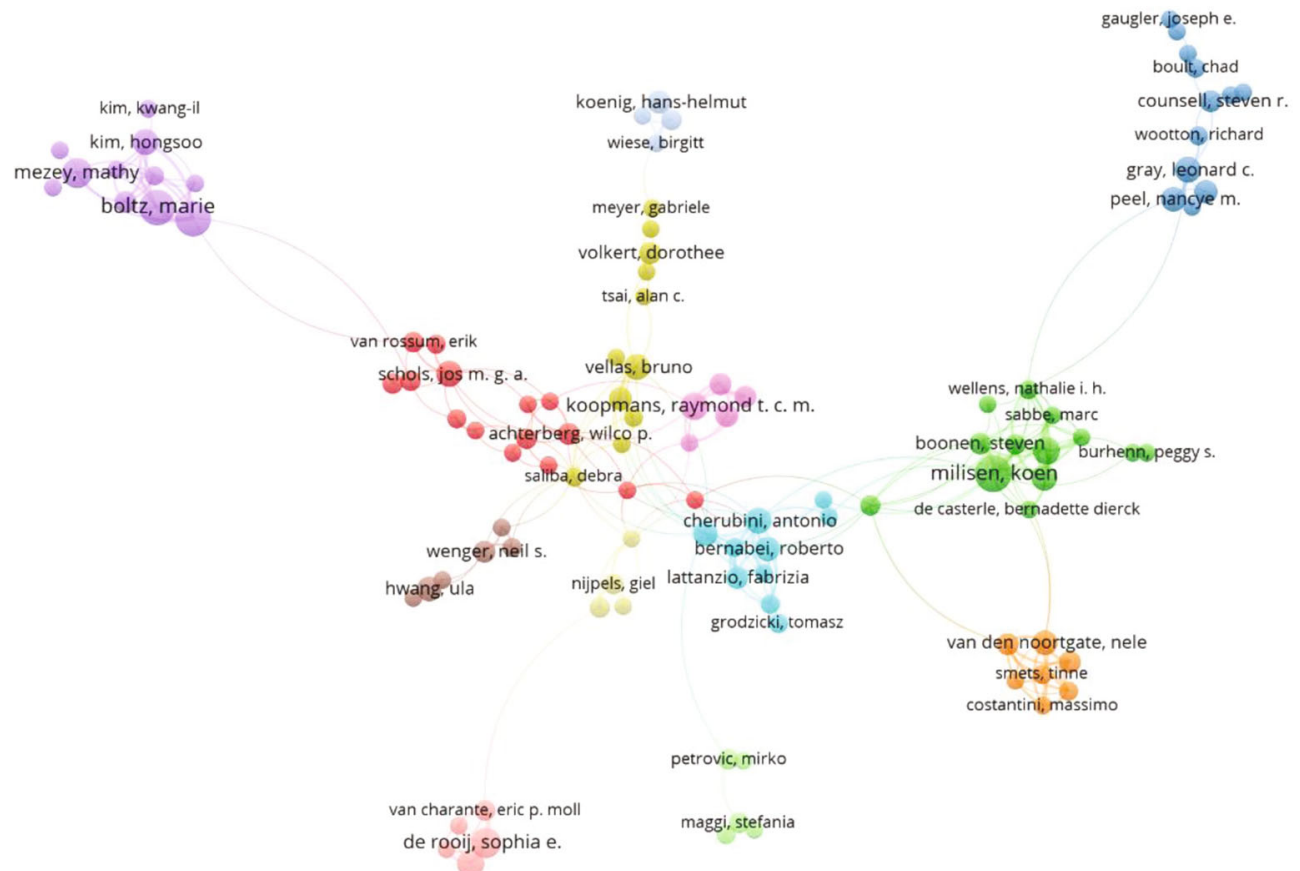

FIGURE 4: Visualization of research networks of authors with a minimum of 5 papers on Geriatric Nursing (1990-2020). Authors in the same cluster had close research interests.

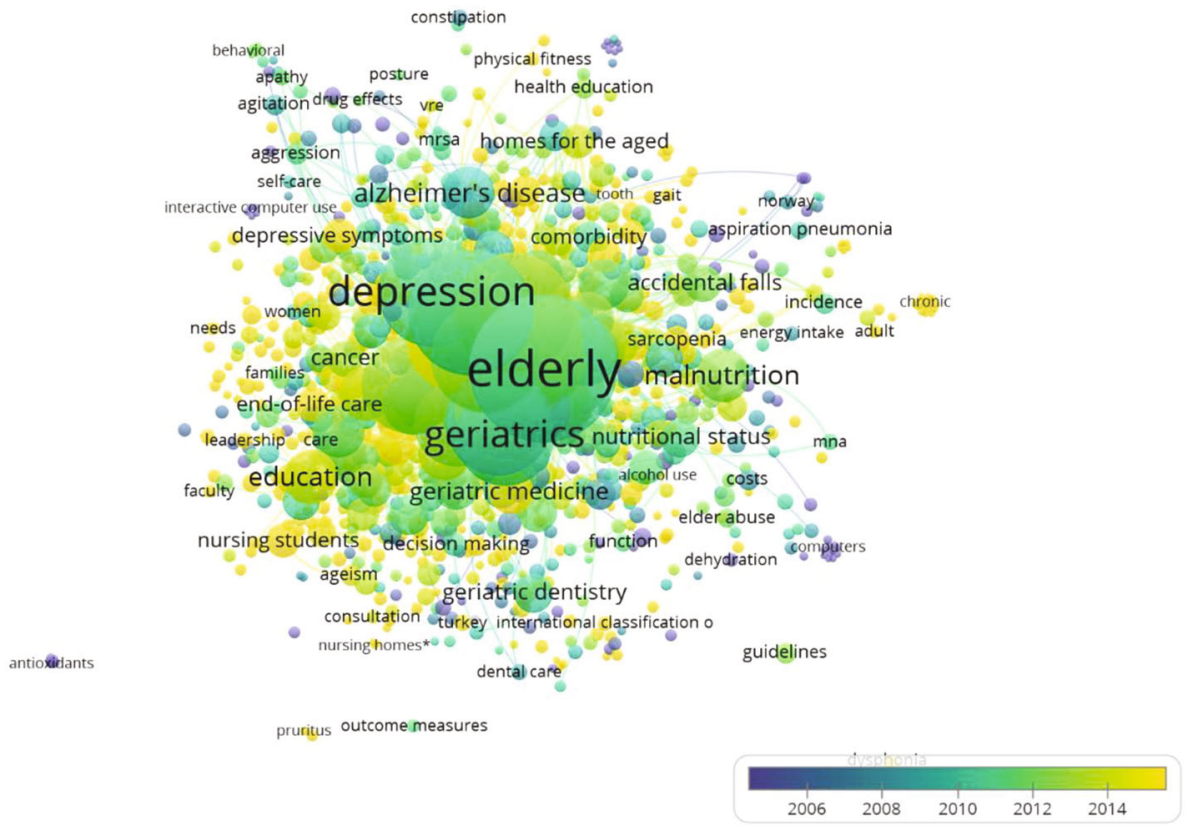

FiguRE 5: Network visualization map of most frequent terms in authors' keywords of the retrieved literature on Geriatric Nursing (1990-2020).

publication of articles after 1990. Moreover, with the fast development of mass media and technology, people receive overt medical data [30]. The rate of citation to articles in this period increased in proportion to the number of articles published. The peak of citations was in 1995. The growth rate of publications from the third period compared to the previous two periods rose significantly and had a rapid expansion. Antunez and Henry showed that the publication of geriatric nursing articles peaked in 2009 with sixty articles, and the articles received citations nearly 280 times [8]. One of the reasons that publications increased in this period could be that in 2009, several scholars and their colleagues created an alumni organization to use their academic and leadership training for advancing gerontological nursing 
TABle 4: 10 most cited papers on Geriatric Nursing (1990-2020).

\begin{tabular}{|c|c|c|}
\hline Title & Year & Citations \\
\hline A multidisciplinary intervention to prevent the readmission of elderly patients with congestive-heart-failure & 1995 & 1571 \\
\hline $\begin{array}{l}\text { Rating chronic medical illness burden in geropsychiatric practice and research - application of the cumulative illness } \\
\text { rating-scale }\end{array}$ & 1992 & 1283 \\
\hline The mini nutritional assessment (MNA) and its use in grading the nutritional state of elderly patients & 1999 & 874 \\
\hline Hazards of hospitalization of the elderly & 1993 & 848 \\
\hline Hazards of hospitalization of the elderly & 1996 & 822 \\
\hline Management of pain in elderly patients with cancer & 1998 & 752 \\
\hline The effects of exercise training on elderly persons with cognitive impairment and dementia: A meta-analysis & 2004 & 741 \\
\hline $\begin{array}{l}\text { Diagnosis and treatment of Alzheimer disease and related disorders - Consensus statement of the American Association } \\
\text { for Geriatric Psychiatry, the Alzheimer's Association, and the American Geriatrics Society }\end{array}$ & 1997 & 696 \\
\hline Validation of the cumulative illness rating-scale in a geriatric residential population & 1995 & 659 \\
\hline Functional Status of Elderly Adults before and after Initiation of Dialysis & 2009 & 590 \\
\hline
\end{tabular}

TABLE 5: 20 active journal papers on Geriatric Nursing (1990-2020).

\begin{tabular}{|c|c|c|c|c|c|}
\hline Journal & Frequency & $\begin{array}{c}\% \\
N=4923\end{array}$ & Country & Impact factor & Quartile in category \\
\hline Journal of the American Geriatrics Society & 373 & 7.57 & USA & 4.180 & Q1 \\
\hline Journal of the American Medical Directors Association & 130 & 2.64 & USA & 4.367 & Q1 \\
\hline Geriatric Nursing & 106 & 2.15 & USA & 4.367 & Q1 \\
\hline Journal of Clinical Nursing & 93 & 1.88 & England & 1.972 & Q1 \\
\hline European Geriatric Medicine & 93 & 1.88 & USA & 1.232 & Q4 \\
\hline International Journal of Geriatric Psychiatry & 93 & 1.88 & England & 2.675 & Q3 \\
\hline BMC Geriatrics & 86 & 1.74 & England & 3.077 & Q2 \\
\hline Journal of Gerontological Nursing & 84 & 1.70 & USA & 1.016 & Q3 \\
\hline Journal of Advanced Nursing & 80 & 1.62 & USA & 2.561 & Q1 \\
\hline Archives of Gerontology and Geriatrics & 78 & 1.58 & Ireland & 2.128 & Q3 \\
\hline Journal of Nutrition Health and Aging & 68 & 1.38 & France & 2.791 & Q3 \\
\hline Age and Ageing & 64 & 1.30 & England & 4.902 & Q1 \\
\hline Educational Gerontology & 62 & 1.25 & USA & 0.621 & Q4 \\
\hline International Journal of Nursing Studies & 60 & 1.21 & England & 3.783 & Q1 \\
\hline Revista da Escola de Enfermagem da USP & 54 & 1.09 & Brazil & 0.798 & Q4 \\
\hline International Psychogeriatrics & 53 & 1.07 & USA & 2.940 & Q1 \\
\hline Geriatrics and Gerontology International & 49 & 0.99 & Japan & 2.022 & Q3 \\
\hline Aging Clinical and Experimental Research & 46 & 0.93 & Italy & 2.697 & Q3 \\
\hline Aging and Mental Health & 46 & 0.93 & England & 2.478 & Q3 \\
\hline American Journal of Geriatric Psychiatry & 45 & 0.91 & USA & 3.393 & Q2 \\
\hline
\end{tabular}

[30]. The maximum growth of articles was in 2018. This indicates that in recent years, more researchers have been interested in researching this field and solving related problems and issues, and other potential reasons may be the increase in the aging world population and changes in countries' policies and their attention to issues related to the elderly and increasing medical care costs. It could relate to more researchers specializing in geriatric nursing. The spectrogram of the number of citations and papers has shown that although the volume of articles has increased slightly in the last decade, the citation rate has decreased. In other words, it has been less popular with other readers. In this period, the growth rate of articles shows a completely inverse relationship with the growth rate of citations. The quality of research in geriatric nursing should be considered.

The spectrogram of the number of citations and number of coauthors showed that, with an increase in the number of authors, the mean citations also increase. The size of research groups and the scientific impact in terms of citations considerably correlate with each other. Team size and citations have a close relationship, as confirmed by this study. This finding is supported by the results of another study that showed the median citations to articles increase with team size [31]. 
The current study indicated that the USA was a pioneer in this field. This was not unusual because the U.S. is the most active country in the study of geriatric nursing, and U.S. researchers rank first when it comes to scientific production in medicine, health, and nursing [30, 32, 33]. Additionally, it was revealed that the large scientific community, big research budget, higher national self-citation, desire to publish in national journals, and developed country are also contributing factors in the USA being a pioneer in this field $[34,35]$. In the USA, the population age sixty-five years and over is estimated to nearly double over the next three decades, from 48 million to 88 million by 2050 , and the need for more research in this field is felt. A decade ago, the Institute of Medicine published its groundbreaking report: Retooling for an Aging America: Building the Health Care Workforce (2008). This report emphasized the need to increase the number of health care providers competent in providing high-quality care for the ever-growing elderly population [36]. According to previous findings, it seems possible that these results are related to America's size and economic strength [27]. Based on the results, we can state that Brazil, Italy, England, France, Sweden, Netherlands, Germany, Australia, Canada, and the USA are among the countries that comprise $81 \%$ of all articles to geriatric nursing. Previous nursing literature shows that the term advanced practice is prevalent, and most of the current nursing literature comes from countries with a higher income (Australia, Canada, USA, Ireland, New Zealand, and South Africa) [37].

Moreover, countries such as the Netherlands, England, Canada, the USA, and Australia have a long history in nursing [9]. These factors could be why they are pioneers in geriatric nursing.

The results showed that Asian and African countries were not active in producing research in geriatric nursing. Since healthcare systems in these regions are rapidly evolving, it is essential to look at the scopes of practice of other nursing roles and how they interact with one another. Moreover, how these scopes evolve should be understood in lower-income countries in which regulatory processes are often underdeveloped [38]. In Asian countries, taking care of the elderly by their children at home is embedded in their culture. In such conditions, geriatric issues are less discussed at the societal level and, thus, are not paid that much attention to and are not considered a priority. Therefore, related research is scarce. In contrast to previous research [39], China was not among the pioneering countries, which supports this assumption. Seven out of ten institutes in the list of geriatric nursing research were from America. Based on the assessments of more than two decades in America, the results reveal the need for increasing the capacity of gerontological nursing in the USA on growing daily basis [30]. This is probably the reason why these institutes have tended towards geriatric nursing research. Secondly, the John A. Harford Foundation designed and implemented the Building Academic Geriatric Nursing Capacity Program in 2000 to emphasize the importance of gerontological nursing on society's health [40]. Moreover, the American Academy of Nursing plays a leading role in the development and imple- mentation of geriatric nursing programs and creating the Building Academic Geriatric Nursing Capacity Program in American universities [40]. Many institutes and universities in America such as the Association for Gerontology in Higher Education, Gerontological Advanced Practice Nurses Association, National Hartford Center of Gerontological Nursing Excellence, the New York University's Rory Meyers, American Association for Colleges of Nursing, and the College of Nursing's Hartford Institute for Geriatric Nursing have strived to enhance geriatric nursing research. Shortly after, many American universities have made significant efforts to design educational frameworks to create stronger gerontological education for nurse generalists [41]. These initiatives have created many advantages for the elderly.

Canadian and Swedish institutions have played a prominent role alongside American institutions. Geriatric nursing is one of the fields in which scientific cooperation, especially at the international level, will help its development. The geographical distance seems to explain some of these international scientific collaborations. The closer the fellow researchers are to a geographical area, the more likely they are to form a research team. Twenty-eight papers were authored by Stig Karlsson, one of the most influential scientists in the field of geriatric nursing, from the Department of Nursing of Umea University. After Stig Karlsson, as the most prolific writer, the next ranks are held by writers from Belgium and Sweden. The results showed that half of the prolific authors were from the Scandinavian countries. The present study identified the willingness of Scandinavian writers, including Sweden, Belgium, and Finland, to study geriatric nursing. Perhaps the reason for this is the adoption of supportive policies at the top management levels in these countries. Top-level managers and politicians in Scandinavia have predicted that nursing competence at higher levels is necessary for meeting the complex needs of the elderly [42]. More and more Scandinavian researchers have begun to focus only on geriatric nursing studies. The support of the Scandinavian countries for geriatric nursing programs is evident in the scientific activities of their researchers. The researchers introduced in the present study are among the leaders in geriatric nursing research, and following their research can be both instructive for other interested researchers and can be used to design future research.

The results showed that the authorship clusters formed are usually influenced by the geographical distance and the joint institution. For example, as seen in Table 3, the top researchers are in the pale green cluster from Umea University in Sweden while the pale orange cluster from Katholieke Universiteit Leuven in Belgium. Authors who are geographically close to each other are more likely to form scientific research collaborations.

By studying the author keywords, it can be inferred that researchers are more motivated to study themes such as dementia, malnutrition, education, depression, and Alzheimer's disease. In all periods, geriatric nursing researchers have studied these topics more than any other themes. By extracting and introducing emerging topics, we can highlight future directions. Therefore, future researches with a focus on COVID-19, interprofessional, locomotive syndrome, 
public health, and emergency nursing are suggested. The most cited article was "A multidisciplinary intervention to prevent the readmission of elderly patients with congestiveheart-failure" in 1995 with 1571 citations. It showed that a nurse-directed, multidisciplinary intervention could increase the quality of life and reduce hospital use and medical costs for elderly patients with congestive heart failure. Most cited papers were published in the second period (1991-2010). In this period, the growth of articles and citations shows a fixed pattern. The topics of this period are still of interest to researchers and readers. The articles of this period show better performance than the first and third periods. In addition, it shows that the flow of geriatric nursing information has been higher during this period. Since citations increase over time, older articles have a longer time to gain citations and have more advantage over their young peers [43]. No rapid changes were observed in this field. The changes were more gradual.

The journals that publish the most geriatric nursing articles were identified. The present study showed that active journals all have a high impact factor based on the journal citation reports (JCR). Researchers can access a large part of geriatric nursing texts by following the journals listed. The American Geriatrics Society has a professional journal for geriatric nursing scientists. One journal in the field of psychology (International Psychogeriatrics) in the active journals list emphasizes the importance of psychology in geriatrics.

The presence of articles in different categoric quartiles may confirm the claim that the field of aging is multidisciplinary. It is also inferred from the distribution of articles in different quartiles that research with the Team Science approach in geriatric nursing will be very fruitful. Issues related to geriatrics will be solved using a multidisciplinary approach.

\section{Strength and Limitations}

The current study is the first bibliometric study to investigate research activity on geriatric nursing. Geriatric nursing articles were reviewed over a long period of nearly seven decades. The names of the authors of the articles may be written in different ways; to achieve the correct results, the authors who used different names were joined together and then analysed. We only used the WoS database; therefore, future studies can use the SCOPUS database or Google Scholar. Another limitation was that only English language research was included in the study.

\section{Conclusions}

In the current study, scientific literature on geriatric nursing was assessed and analyzed. Geriatric nursing is an established and a mature field and has received increasing attention in the last decade. It is necessary to pay more attention to the quality of texts in recent years, in line with the slight growth of geriatric nursing texts. The USA and American institutions play an active role in geriatric nursing. Aging populations have affected a wide range of countries in the world, and in addition to leading countries in this field, some developing countries have paid attention to geriatric nursing by publishing scientific articles in recent years. Geriatric nursing is one of the subject areas that can flourish through international collaborations and contributions of authors. By introducing research themes, highly cited articles, and active journals, the results can be useful for future research. Policymakers, especially in developing countries, should pay attention to geriatric nursing as a specialty of nursing both as a discipline of research and as a profession to solve aging issues they would face considering the increasing elderly population.

\section{Data Availability}

The data used to support the findings of this study are included within the article.

\section{Conflicts of Interest}

The authors declare that they have no conflicts of interest.

\section{Authors' Contributions}

LNA, AGH, and MZ conceived and designed the study. $\mathrm{AGH}$ and $\mathrm{MZ}$ gathered the data. LNA and $\mathrm{AGH}$ extracted the data and analyzed the results. LNA, MZ, and AGH were involved in the analyses and interpretation. LNA were involved in drafting the manuscript. All authors drafted the manuscript, revised the final version, and approved it for submission.

\section{Acknowledgments}

The authors would like to express their gratitude and sincere appreciation to Dr. Shahla Bahavar for her significant contributions on editing the manuscript and providing research support. This work was supported by funding from Iran University of Medical Sciences (No. 16008.IR.IUMS.REC.1398.1301).

\section{References}

[1] B. Osborne, D. Bakula, M. Ben Ezra et al., "New methodologies in ageing research," Ageing Research Reviews, vol. 62, no. 6, p. 101094, 2020.

[2] P. L. Hsieh and C. M. Chen, "Nursing competence in geriatric/long term care curriculum development for baccalaureate nursing programs: a systematic review," Journal of Professional Nursing, vol. 34, no. 5, pp. 400-411, 2018.

[3] D. Melzer, L. C. Pilling, and L. Ferrucci, "The genetics of human ageing," Nature Reviews Genetics, vol. 21, no. 2, pp. $88-101,2020$.

[4] C. Lopez-Otin, M. A. Blasco, L. Partridge, M. Serrano, and G. Kroemer, "The hallmarks of aging," Cell, vol. 153, no. 6, pp. 1194-1217, 2013.

[5] United, Nations, World Population Ageing 2019 Highlights, United Nations, New York, 2019.

[6] A. Y. Chang, V. F. Skirbekk, S. Tyrovolas, N. J. Kassebaum, and J. L. Dieleman, "Measuring population ageing: an analysis of 
the Global Burden of Disease Study 2017," The Lancet Public Health, vol. 4, no. 3, pp. E159-e167, 2019.

[7] K. Antypas and M. Kirkevold, "Structure evaluation of the implementation of geriatric models in primary care: a multiple-case study of models involving advanced geriatric nurses in five municipalities in Norway," BMC Health Services Research, vol. 20, no. 1, pp. 2-16, 2020.

[8] M. Y. Antunez and M. Henry, "A comparative review of gerontological nursing citation data," Health Information and Libraries Journal, vol. 33, no. 4, pp. 257-268, 2016.

[9] E. Boman, A. L. Glasberg, R. Levy-Malmberg, and L. Fagerstrom, "Thinking outside the box': advanced geriatric nursing in primary health care in Scandinavia," BMC Nursing, vol. 18, no. 1, pp. 1-9, 2019.

[10] S. N. Andreassen, M. B. Ezra, and M. Scheibye-Knudsen, "A defined human aging phenome," Aging, vol. 11, no. 15, pp. 5786-5806, 2019.

[11] P. A. Holkup, "The 20th century. Looking back at the ambiance of aging from the perspective of age-specific journals and periodicals," Journal of Gerontological Nursing, vol. 27, no. 6, pp. 38-46, 2001.

[12] C. Mueller and R. A. M. Watry, "40 years of research studies published in _Geriatric Nursing_," Geriatric Nursing, vol. 41, no. 1, pp. 38-39, 2020.

[13] L. Bornmann, R. Haunschild, and L. Leydesdorff, "Reference publication year spectroscopy (RPYS) of Eugene Garfield's publications," Scientometrics, vol. 114, no. 2, pp. 439-448, 2018.

[14] Z. Q. Wang, W. Glanzel, and Y. Chen, "The impact of preprints in Library and Information Science: an analysis of citations, usage and social attention indicators," Scientometrics, vol. 125, no. 2, pp. 1403-1423, 2020.

[15] J. M. Merigo, C. A. Cancino, F. Coronado, and D. Urbano, "Academic research in innovation: a country analysis," Scientometrics, vol. 108, no. 2, pp. 559-593, 2016.

[16] W. W. Hood and C. S. Wilson, "The literature of bibliometrics, scientometrics, and informetrics," Scientometrics, vol. 52, no. 2, pp. 291-314, 2001.

[17] J. Moretto, C. Girard, and C. Demougeot, "The role of arginase in aging: a systematic review," Experimental Gerontology, vol. 116, no. 14, pp. 54-73, 2019.

[18] R. Takahashi and Y. Kajikawa, "Computer-aided diagnosis: a survey with bibliometric analysis," Int J Med Inform, vol. 101, no. 5, pp. 58-67, 2017.

[19] I. Tahamtan, A. S. Afshar, and K. Ahamdzadeh, "Factors affecting number of citations: a comprehensive review of the literature," Scientometrics, vol. 107, no. 3, pp. 1195-1225, 2016.

[20] L. Bornmann, R. Mutz, C. Neuhaus, and H. D. Daniel, "Citation counts for research evaluation: standards of good practice for analyzing bibliometric data and presenting and interpreting results," Ethics in Science and Environmental Politics, vol. 8, no. 1, pp. 93-102, 2008.

[21] C. Birkle, D. A. Pendlebury, J. Schnell, and J. Adams, "Web of Science as a data source for research on scientific and scholarly activity," Quantitative Science Studies, vol. 1, no. 1, pp. 363376, 2020.

[22] N. J. Van Eck and L. Waltman, "Text mining and visualization using VOSviewer,” ISSI Newsletter, vol. 7, no. 3, pp. 50-554, 2011.

[23] S. C. Bradford, "Sources of information on specific subjects 1934," Journal of Information Science, vol. 10, no. 4, pp. 176180, 1985.
[24] D. M. Marchiori, S. Popadiuk, E. W. Mainardes, and R. G. Rodrigues, "Innovativeness: a bibliometric vision of the conceptual and intellectual structures and the past and future research directions," Scientometrics, vol. 126, no. 1, pp. 5592, 2021.

[25] B. C. Andre, "Geriatric nursing programs in schools of nursing," J Gerontol, vol. 8, no. 1, pp. 90-93, 1953.

[26] B. Winblad, P. Amouyel, S. Andrieu et al., "Defeating Alzheimer's disease and other dementias: a priority for European science and society," Lancet Neurology, vol. 15, no. 5, pp. $455-532,2016$.

[27] S. H. Zyoud, "Global research trends of Middle East respiratory syndrome coronavirus: a bibliometric analysis," BMC Infectious Diseases., vol. 16, p. 7, 2016.

[28] W. M. Sweileh, "Global research activity on elder abuse: a bibliometric analysis (1950-2017)," J Immigr Minor Health, vol. 23, no. 1, pp. 79-87, 2021.

[29] M. E. Campbell, "Study of the attitudes of nursing personnel toward the geriatric patient," Nursing Research, vol. 20, no. 2, pp. 147-151, 1971.

[30] P. Kokol and H. B. Vosner, "Historical, descriptive and exploratory analysis of application of bibliometrics in nursing research," Nursing Outlook, vol. 67, no. 6, pp. 680-695, 2019.

[31] L. F. Wu, D. S. Wang, and J. A. Evans, "Large teams develop and small teams disrupt science and technology," Nature, vol. 566, no. 7744, pp. 378-382, 2019.

[32] S. Adnan and R. Ullah, "Top-cited articles in regenerative endodontics: a bibliometric analysis," J Endod, vol. 44, no. 11, pp. 1650-1664, 2018.

[33] W. M. Sweileh, "Global research output on HIV/AIDS-related medication adherence from 1980 to 2017," BMC Health Services Research, vol. 18, no. 1, pp. 1-13, 2018.

[34] F. M. Campbell, "National bias - a comparison of citation practices by health-professionals," Bulletin of the Medical Library Association, vol. 78, no. 4, pp. 376-382, 1990.

[35] H. Shi, C. Mao, J. L. Tang, and H. Y. Liang, "Research on the health of and interventions for family caregivers of people with dementia: a bibliometric analysis of research output during 1988-2018," BMC Geriatric, vol. 20, no. 1, pp. 1-9, 2020.

[36] J. E. Farley, J. Stewart, J. Kub, C. Cumpsty-Fowler, K. Lowensen, and K. Becker, "Development of The Johns Hopkins University School of Nursing adult/geriatric primary care nurse practitioner program in HIV prevention, treatment, and care," The Journal of the Association of Nurses in AIDS Care, vol. 27, no. 3, pp. 223-233, 2016.

[37] D. C. Benton, L. Cusack, R. Jabbour, and C. Penney, "A bibliographic exploration of nursing's scope of practice," International Nursing Review, vol. 64, no. 2, pp. 224-232, 2017.

[38] D. C. Benton, M. P. Fernandez-Fernandez, M. A. GonzalezJurado, and J. V. Beneit-Montesinos, "Analysis of a global random stratified sample of nurse legislation," International Nursing Review, vol. 62, no. 2, pp. 207-217, 2015.

[39] J. J. Lee and J. P. Haupt, "Scientific globalism during a global crisis: research collaboration and open access publications on COVID-19," Sci Educ (Dordr), vol. 81, no. 5, pp. 949-966, 2021.

[40] J. van Cleave, S. L. Szanton, C. Shillam et al., "Hartford gerontological nursing leaders: from funding initiative to national organization," Journal of Professional Nursing, vol. 32, no. 1, pp. $25-31,2016$. 
[41] L. A. Plowfield, J. E. Raymond, and E. R. Hayes, "An educational framework to support gerontological nursing education at the baccalaureate level," Journal of Professional Nursing, vol. 22, no. 2, pp. 103-106, 2006.

[42] E. Finnbakk, K. Skovdahl, E. S. Blix, and L. Fagerström, “Toplevel managers' and politicians' worries about future care for older people with complex and acute illnesses - a Nordic study," International Journal of Older People Nursing, vol. 7, no. 2, pp. 163-172, 2012.

[43] Y. A. Wang, A. Zeng, Y. Fan, and Z. R. Di, "Ranking scientific publications considering the aging characteristics of citations," Scientometrics, vol. 120, no. 1, pp. 155-166, 2019. 